\title{
DOSSIÊE
}

Sociologias, Porto Alegre, ano 15, no 32, jan./abr. 2013, p. 94-110

\section{Governança Global Democrática, Desigualdade Política e a Hipótese da Resistência Nacionalista}

\section{Resumo}

Será a governança global inevitável? Será possível uma governança global democrática? Aponto dois obstáculos para a existência desta: a desigualdade política e a resistência nacionalista. Enquanto a governança global já existe, uma governança global democrática é refreada por desigualdades políticas internas e entre nações. Neste contexto, a resistência nacionalista, refreamento e desvio em direção ao unilateralismo, através da qual as nações evadem-se às estratégias de governança global, também se apresenta como um desafio ao desenvolvimento democrático de instituições deste cunho. Este artigo pretende dar continuidade ao diálogo entre sociólogos e outros cientistas sociais sobre a esperança otimista pela governança global.

Palavras-chave: Governança global. Democracia. Desigualdade política. Problemas globais.

\footnotetext{
* Professor Assistente no Instituto de Filosofia e Sociologia da Academia Polonesa de Ciências. Coordenador do Projeto Cross-National Studies: Interdisciplinary Research and Training Program (CONSIRT). (Polônia).

E-mail: dubrow.2@osu.edu
} 
Sociologias, Porto Alegre, ano 15, no 32, jan./abr. 2013, p. 94-110

\title{
Democratic Global Governance, Political Inequality, and the Nationalist Retrenchment Hypothesisv
}

\begin{abstract}
Is global governance inevitable? Is democratic global governance likely? I point out two obstacles that lie in the path toward democratic global governance: political inequality and nationalist retrenchment. While global governance is already here, democratic global governance is held back by political inequality within and between nations. In this context, nationalist retrenchment, a stop and backslide toward unilaterialism where nations eschew global governance strategies, also poses a challenge to the democratic development of global governance institutions. This article serves to continue the conversation among sociologists and other social scientists on the optimistic hopes for democratic global governance.
\end{abstract}

Keywords: Global governance. Democracy. Political inequality. Global issues.

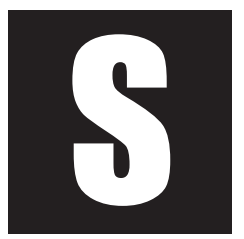

erá a governança global inevitável? Será possível uma governança global democrática? Neste texto, aponto dois obstáculos para a existência desta: a desigualdade política e a resistência nacionalista.

O presente artigo, assim como a presente edição de Sociologias, foi inicialmente inspirado por dois eventos durante o Congresso Mundial da ISA -International Sociological Association, em Gotemburgo, na Suécia (2010). O primeiro evento inspirador foi uma fala do conferencista da Primeira Sessão Presidencial, Yuan-Tseh Lee, de Taiwan, vencedor de um Prêmio Nobel ${ }^{1}$.

\footnotetext{
v Tradução de Liana V. Fernandes. asapalavra@gmail.com

${ }^{1}$ Ocorrida no dia 12 de julho, segunda-feira, entre 08:45 e 13:00. Grande parte dessa fala de Lee está transcrita em "Challenges Facing Human Society in the 21st Century", um capítulo do livro Facing an Unequal World: Challenges for a Global Sociology, Volume 1 (2010), que também será citado aqui. O livro está disponível online gratuitamente e basta usar uma boa ferramenta de busca para encontrá-lo.
} 
Durante 45 minutos, em uma plenária com três quartos da lotação ocupados, Lee afirmou que a humanidade segue um rumo preocupante. Estamos todos interconectados por meio do ambiente natural e dos processos de globalização, disse Lee. Nossa humanidade inter-relacionada combina um modo de vida insustentável com uma industrialização acelerada e os resultados são pandemias e mudanças climáticas globais, escassez de alimentos e água em algumas regiões e desperdício dos mesmos em outras. Lee convocou a ciência a encontrar uma saída. Um problema crucial para essa solução é que o avanço e a competitividade científicos são desenvolvidos para satisfazer necessidades nacionais ou, estritas questões internacionais. Parafraseando Lee: os cientistas vão a congressos, prometem colaboração internacional e, depois, voltam para casa. Em casa, o governo pergunta, "Essa colaboração internacional aprimorará a competitividade nacional no mercado global?"; ou a União Europeia pergunta, "Isso trará vantagens à UE?" Se o cientista responder "não", os governos não demonstrarão entusiasmo.

Para que a ciência e a tecnologia resolvam os problemas enfrentados pelo homem no século 21, não basta que ambas avancem em ritmo acelerado. [...] os problemas sérios relacionados ao desenvolvimento sustentável não serão resolvidos, a menos que [...] aprendamos a trabalhar juntos para além das fronteiras nacionais e prestemos mais atenção à nossa 'competitividade global' coletiva para solucionar os problemas de todo o mundo, ao invés de continuarmos preocupados apenas com a 'competitividade nacional' de nossos próprios países (Lee, 2010, p. 33).

Para livrar a ciência desta subordinação ao interesse próprio nacional, Lee preconiza um tipo de governo global:

À medida que o mundo se torna mais e mais globalizado, fica evidente a necessidade de algo como um 'governo global' que possa resolver o conflito entre os interesses dos estadosnação e os interesses de todo o mundo (Lee, 2010, p. 33). 
O segundo evento inspirador foi uma sessão $A d H_{o c}^{2}$ sobre "Democratização da Governança Global", organizada por Christopher Chase-Dunn e por Alberto Martinell, ex-presidente da ISA. Chase-Dunn e Martinelli descreveram a sessão como uma abordagem de questões conceituais e empíricas no estudo da governança global e dos esforços históricos e contemporâneos para a democratização do sistema global ${ }^{3}$. Refletindo a importância do tema, a sessão ocorreu em um dos principais recintos do Congresso, em um auditório amplo com um largo palco, sistema de som profissional e uma enorme tela de projeção. A sessão contou com boa audiência (entre 50 a 75 pessoas), indício de grande interesse para uma palestra listada nas páginas finais da programação da ISA ${ }^{4}$. Embora tivesse escopo internacional, a sessão exibiu predominância de acadêmicos americanos: dentre os documentos distribuídos, quatro dos oito eram de instituições acadêmicas dos Estados Unidos. A sessão consistiu de cinco apresentações e, ao final, um espaço para perguntas e respostas. Entre os apresentadores, estavam John Markoff, com "Democracia Nacional e Global", e Peter Evans, com "Democratização da Governança Global". Markoff argumentou que o que consideramos democracia é uma noção historicamente situada e inerentemente discriminatória (em suas palavras: Democracia para nós, não para eles. Ver também Markoff, 1999 e esta

\footnotetext{
2Segundo a ISA, sessões Ad Hoc são aquelas que "não se enquadram propriamente" à estrutura normal da ISA. A associação impõe regras muito mais rígidas para a inclusão de sessões Ad Hoc; pelo menos, bem mais rígidas do que aquelas impostas às sessões que "se ajustam" à ISA. Conforme a ISA, "para qualificar-se a um horário na programação do Congresso, a sessão [Ad $\mathrm{Hoc}$ ] em potencial deve envolver um número substancial de sociólogos de diversos países, que já estejam envolvidos com alguma colaboração e cujos interesses específicos não se enquadrem propriamente ao campo de um Comitê de Pesquisa, ou a um Grupo de Trabalho ou Temático estabelecidos pela ISA". Não é difícil imaginar "Governança Global Democrática" enquadrando-se à RC18: Sociologia Política. Portanto a designação "Ad Hoc" é mais organizacional do que temática.

${ }^{3}$ CONGRESS Programme. ISA WORLD CONGRESS OF SOCIOLOGY, 17. Gothenburg, 2010. Disponível em: <http://www.isa-sociology.org/congress2010/adh/index.htm>. Acesso em: 20 jul. 2010.

${ }^{4}$ Na página 323 de 359, com três das páginas finais destinadas a anotações.
} 
edição de Sociologias). A tese principal de Markoff é de que, devido à globalização e outros processos de interconexão, os problemas nacionais - da proliferação nuclear e terrorismo internacional a mudanças climáticas globais - abrem caminho, inevitavelmente, a processos de governança trans ou internacional. Os apresentadores especularam sobre o futuro, no qual todos os caminhos levam à governança global.

Durante essa sessão, dirigi uma pergunta a John Markoff, mas a mesma se aplicava a todas as palestras. Meu comentário foi formulado nos seguintes termos:

Você diz que a governança transnacional é inevitável [...] por que não seria a resistência nacionalista o resultado inevitável? Por exemplo, embora os problemas se tornem cada vez mais transnacionais - e, neste ponto, concordo com você - nos Estados Unidos, o movimento 'EUA fora da ONU!' vem crescendo. Sua tese sobre o futuro está baseada em otimismo?

Em resposta, Markoff observou que esta é uma pergunta recorrente sempre que ele expõe sua teoria e argumentou que, deliberadamente, não afirmou que a governança será eficaz, ou mesmo democrática. Em termos básicos, problemas globais impactam simultaneamente muitas nações, fato que faz da governança global a solução prática inevitável. Contudo, ele tem esperança em uma governança global democrática. Peter Evans também respondeu ao que chamou de hipótese da resistência nacionalista, conferindo um tom humorístico ao tema. Em suas palavras: [s]e houvesse um Conselho Intergaláctico apostando no destino da humanidade na Terra, apostariam na extinção; qualquer um que examinasse essa situação apostaria na resistência nacionalista. O comentário de Evans deixava claro: a governança global democrática baseia-se no otimismo. Levando em consideração o conteúdo das apresentações de Markoff e Evans, eu diria que a sessão fundamentou-se em um "pragmatismo otimista" Obamiano, em que os atores agem como se estivessem baseados em uma realidade preocupante, mas ainda manifestam esperanças por um futuro melhor.

Nessa conferência, como cientista, assumi o compromisso de colaborar com meus colegas em âmbito internacional e, então, retornei ao meu país. Lá, estava 
em meio ao processo de coedição - com a professora Soraya Vargas Côrtes, da Universidade Federal do Rio Grande do Sul, de Porto Alegre, Brasil - de um número especial do International Journal of Sociology (IJS), tendo por tema "Political Inequality in Latin America" (Desigualdade Política na América Latina). A edição do IJS reúne, em um volume, artigos baseados em estudos empíricos de acadêmicos latino-americanos sobre a forma, as causas e consequências da desigualdade política na América Latina (Cortes; Dubrow, 2011). Nesta publicação, definimos desigualdade política como uma questão de quem influencia as decisões dos organismos responsáveis pelas mesmas. Consideramos a desigualdade política como um conceito multidimensional - englobando voz e reação - que ocorre em todos os tipos de estrutura de governança, de organizações do movimento social a governos locais e nacionais, até a governança global. Voz refere-se a como o público comunica seus interesses aos tomadores de decisão, seja diretamente ou através de representantes. Reação refere-se a como os tomadores de decisão agem e reagem em relação ao seu público e assume as formas de representações simbólicas e de políticas. Um conceito flexível de desigualdade política, argumentamos, pode ser aplicado às distintas nações e a diferentes épocas, bem como a todos os tipos de sistemas de tomada de decisão política.

Com esses eventos e projetos em mente, tornou-se claro para mim que, ao longo da rota para a governança global democrática, encontram-se os obstáculos da desigualdade política entre nações e dos interesses nacionalistas dentro das mesmas. Este artigo começou como um ensaio curto, que delineava tais obstáculos; enviei-o por e-mail a Markoff, Chase-Dunn e Evans, os quais gentilmente responderam com rapidez e comentários perspicazes. Quando Professora Soraya Cortes e eu comunicamos a intenção de criar um dossiê para a revista Sociologias voltado a essas questões, Markoff e Chase-Dunn aceitaram participar.

Para dar continuidade ao debate com esses cientistas, incorporo seus artigos publicados nesta edição de Sociologias em uma discussão ampliada sobre a inevitabilidade da governança global e as possibilidades de uma governança global democrática. 
Primeiramente, abordo a questão da democracia, com argumentos fundados, em grande parte, em Markoff e seu artigo publicado nesta edição sobre o passado, o presente e o futuro da democracia. Markoff aponta que o que entendemos como democracia vem mudando ao longo do tempo. Nossa noção moderna de eleições diretas para todos os principais cargos políticos não era aceitável na democracia ateniense, por exemplo; na verdade, o que cientistas sociais atualmente consideram como democracia mudou radicalmente desde os anos 1780, especialmente nosso desejo por inclusão. Mais do qualquer coisa, a democracia é uma autonomia limitada. $\mathrm{O}$ artigo de Markoff nos lembra de que a democracia sempre esteve restrita por limitações, sejam demográficas (o direito de voto feminino é uma invenção do século 20) ou nacionais ("cidadãos" votam, mas não os não-cidadãos ${ }^{5}$ ), ou mesmo internacionais (apenas um pequeno e seleto grupo de países tem lugar no Conselho de Segurança da ONU). Limitações específicas mudam, mas o uso das mesmas tem sido constante.

Embora seja geralmente um tanto arriscado especular sobre mudanças radicais nos modos de pensar (p. 35), antecipa uma potencial mudança na forma de pensar sobre a democracia em um momento em que nossas superadas noções de fronteiras nacionais entram em colisão com os problemas globais. Assim como Lee (2010), ao tratar dessa questão, Markoff apresenta um rol de iminentes desastres simultâneos, entre os quais se destacam terríveis pandemias globais, criminalidade transnacional, proliferação nuclear, crise econômica mundial e mudanças climáticas globais. Esses problemas não respeitam nossas tão bem protegidas fronteiras nacionais. Para defendermo-nos de desastres, agências transnacionais precisarão ser criadas. Algumas já existem: a Organização das Nações Unidas, a Organização Mundial da Saúde, a Organização Mundial do Comércio e o Fundo Monetário Internacional são alguns dos principais exemplos. A governança global é uma forma

\footnotetext{
${ }^{5}$ Sobre a instituição jurídica da desigualdade de migrantes nos países do MERCOSUL, ver Modolo (2011).
} 
de os países coordenarem ações em frentes múltiplas e simultâneas. Mas não há garantia de que a governança seja democrática.

Markof argumenta que as noções de democracia mudam, porque a democracia permite aos movimentos sociais contestarem as desigualdades do status quo, e são estes movimentos sociais que, como creem Chase-Dunn e Lerro, democratizarão a governança global. O caráter transnacional dos problemas globais, especialmente, exigirá cada vez mais a reação das organizações transnacionais do movimento social, o que então levará à governança global democrática.

Do mesmo modo que Markoff, Chase-Dunn e Lerro veem a democracia da forma como é praticada - repleta de desigualdade política. A preocupação de Chase-Dunn e Lerro é que a maioria das pessoas tem pouca ou nenhuma participação nas decisões tomadas nas estruturas existentes de governança global. Como apontam os autores, não se pode simplesmente somar democracias nacionais e declarar democrática a governança global ${ }^{6}$. Uma verdadeira democracia global é aquela em que a maioria dos povos tem influência significativa sobre as decisões que os atingem. Até o presente momento, isso não existe.

Segundo Chase-Dunn e Lerro (2013), a igualdade política global surge quando o poder na tomada de decisão é separado da posição ocupada no sistema global. Poderes hegemônicos centrais tendem a transmitir decisões à semiperiferia e à periferia. Relações hierárquicas do sistema mundial moderno estão fundamentadas no capitalismo global; este sistema subsidia e controla as atuais estruturas de governança global.

A governança global democrática requer, também, democracia popular direta, caracterizada por uma substancial disseminação da influência política associada a uma pouca verticalidade da estrutura de estratificação política (ver Sorokin, 1957). Historicamente, as organizações de movimentos sociais que de-

\footnotetext{
${ }^{6}$ Vale observar que, enquanto agregar países e regiões capitalistas envolvidos em produção econômica resulta em um sistema mundial capitalista e suas relações hierárquicas, o mesmo processo não se aplica à governança global democrática.
} 
fendem a democracia direta popular emergiram em territórios delimitados entre pequenos grupos que focavam sua energia no próprio país. À medida que as conexões da humanidade se expandem e aprofundam, os movimentos e suas organizações começam a olhar para além das fronteiras. Chase-Dunn e Lerro (2013) argumentam que organizações do movimento social transnacional que defendem a justiça global e a igualdade política devem emergir para instituir a democracia na governança global ${ }^{7}$. Democratizar as instituições de governança global requer que superemos os "déficits democráticos", e Chase-Dunn e Lerro (2013) não são os únicos a acreditar que atores transnacionais possuem grande potencial nesse sentido (p. ex. Weiss; Carayannis; Jolly, 2009; e Bexell; Tallberg; Uhlin, 2010).

\section{Obstáculos no caminho para a governança global democrática}

Volto-me, agora, aos obstáculos interpostos na rota para a governança global democrática, fazendo a primeira e mais óbvia pergunta: Será a governança global inevitável?

Seria útil começar definindo "governança global". Elke Krahmann (2003) analisou vinte anos de literatura acadêmica sobre governança em nível nacional, regional e global, para desvendar como o termo "governança" foi definido. A partir disto, ela selecionou uma definição universal de governança, e vale repeti-la:

[São] as estruturas e processos que permitem a atores governamentais e não governamentais coordenar suas necessidades e interesses interdependentes através da criação e implementação de políticas na ausência de uma autoridade política unificadora (Elke Krahmann, 2003, p. 331).

A ausência de uma autoridade central é a diferença-chave entre "governança" e governo, o último sendo caracterizado pela autoridade política centralizada no estado. Governança global é a regulação de relações internacionais sem uma

\footnotetext{
${ }^{7}$ Chase-Dunn e Lerro (2013) defendem que este desafio inovador ao status quo virá, não do poder central, mas das semiperiferias, as quais, argumentam os autores, têm sido historicamente os principais agentes de inovação global.
} 
autoridade centralizada, significando que os esforços para lidar com necessidades interdependentes são voluntários. Como a governança global compete com a soberania nacional, estados-nação resistem à centralização de muito poder em um só organismo global. Apesar do antagonismo com a soberania nacional, a institucionalização da governança global tem se acelerado; os estados estão cientes de que nenhuma nação isolada será capaz de resolver os problemas mundiais, e a globalização forçou até mesmo os países mais nacionalistas a colaborar além das fronteiras nacionais (Krahmann, 2003, p. 329-30).

Duas hipóteses principais podem responder à questão da inevitabilidade da governança: a hipótese da governança global e a hipótese da resistência nacionalista.

Hipótese da governança global: Quanto mais problemas forem de âmbito mundial, maiores as chances do surgimento e desenvolvimento da governança global.

Segundo Lee (2010), Markoff (2013) e Chase-Dunn e Lerro (2013), alguma forma de governança global é um resultado pragmático de problemas naturais de origem humana em âmbito mundial. $\mathrm{O}$ fato de já termos estruturas de governança global estabelecidas fornece apoio empírico a uma resposta positiva. O mundo acadêmico já declarou a governança global como uma realidade: há um periódico chamado Global Governance ${ }^{8}$ que circula desde o início dos anos 1990.

Uma hipótese alternativa postula um mundo em que ocorre o oposto: apesar dos crescentes problemas globais, as nações irão abster-se de compromissos internacionais os quais acreditem que limitarão sua capacidade de agir por seus próprios interesses localistas. Esta é a hipótese da resistência nacionalista.

\footnotetext{
${ }^{8}$ De acordo com o website do periódico, Global Governance exibe o conhecimento especializado de importantes pesquisadores e profissionais interessados nos processos de cooperação e multilateralismo. O resultado é uma instigante exploração dos desafios transnacionais mais urgentes de nosso tempo -- entre estes, questões de paz e segurança, desenvolvimento, direitos humanos, meio ambiente e saúde [...] A Global Governance é editada em parceria com o Academic Council on the United Nations System (ACUNS). Um comentário de apoio diz, Nós que trabalhamos no sistema das Nações Unidas admiramos a Global Governance pela alta qualidade dos artigos sobre as instituições da ONU [...] -- Edmond Mulet, Secretário Geral Assistente de Operações de Paz das Nações Unidas. Disponível em: < https://www.rienner.com/ title/Global_Governance_A_Review_of_Multilateralism_and_International_Organizations $>$. Acesso em: 04 jul. 2012.
} 
Hipótese da resistência nacionalista: Quanto mais problemas forem de âmbito mundial, maior será a resistência nacionalista.

Utilizo os termos "resistência" e "nacionalista" deliberadamente. Com resistência, denoto um processo de refreamento e de desvio em direção ao unilateralismo, no qual as nações esquivam-se das estratégias de governança global. Com nacionalista, refiro-me a uma visão dos eventos mundiais focada no âmbito da nação, semelhante ao unilateralismo. (Howard, 2010).

A resistência nacionalista pode ser uma mera ficção teórica (theoretical counterfactual), algo que, em sua integralidade, não é possível hoje. Que evidência se tem, na era moderna, da resistência nacionalista? A relação EUA/ONU é um estudo de caso propício. O movimento "EUA fora da ONU!" originou-se na John Birch Society, organismo de extrema direita, e, apesar de algumas revitalizações episódicas, nunca foi uma real ameaça à presença dos EUA na ONU, nem à localização da sede das Nações unidas na cidade de Nova lorque. Não obstante, os Estados Unidos possuem um histórico contencioso com a ONU, vacilando entre o unilateralismo e o multilateralismo (Howard, 2010). Embora o Congresso dos EUA seja historicamente cético em relação às Nações Unidas (Howard, 2010, p. 485), membros conservadores do clube da resistência nacionalista - retrocessos anacrônicos à era pré-Wilsoniana (ou à década de 1930) - são uma classe rara.

O atual consenso é de que algum tipo de governança global é inevitável. Segundo Keohane (2002, p. 2), a globalização torna indispensável um certo grau de regulamentação em nível global. Não é necessário ser um vulgar realista geopolítico (como afirma ter sido chamado Chase-Dunn, 2005) para afirmar que o grau de cooperação econômica pressupõe um tipo de governança global que segue intensificando e interconectando uma rede cada vez mais densa e profunda de nações, sociedades e culturas ${ }^{9}$. De acordo com Evans ${ }^{10}$, o capital mundial assegura o surgimento de uma espécie de governança global, na medida em que as

\footnotetext{
${ }^{9} \mathrm{E}$, possivelmente, uma "névoa de globalização" mais densa e profunda (Chase-Dunn, 2005, p. 172).

${ }^{10}$ Comunicação pessoal, 25 de julho de 2010.
} 
estruturas de governança permitem que o capitalismo mundial sobreviva e prospere. É possível a resistência, dada a dimensão do sistema-mundo capitalista moderno? Há um debate em curso a respeito do caminho, ou trajetória, em direção à governança global. Dentre os debatedores, a maioria afirma que haverá períodos e episódios de resistência nacionalista, mas que mesmo a trajetória mais tortuosa segue em direção à governança global.

Vale enfatizar que o surgimento da governança global como um meio transnacional para solução de problemas não anuncia necessariamente o advento de um governo global. Independente do marco disciplinar ou teórico - relações internacionais e análise de sistemas mundiais, por exemplo - não há indício de um organismo político unificado como esse ameace tornar-se realidade. Alguns poderão argumentar que, mesmo sem um organismo político formal, o sistema de governança, em sua presente forma, opera de maneira muito semelhante a um estado global, no qual alguns poucos países atuam em conjunto para dominar o resto. Embora uma discussão extensiva deste ponto ultrapasse os limites deste curto artigo (ver Chase-Dunn e Lerro (2013), para uma análise mais aprofundada), farei rápida menção ao tema na seção seguinte, sobre governança global democrática.

Se a governança global é inevitável, podemos, então, voltar-nos à próxima questão: Há possibilidades de uma governança global democrática? Aqui, a noção de desigualdade política se mostra importante.

A desigualdade política pode ser considerada tanto uma dimensão da democracia quanto uma dimensão da estratificação social. A maior parte das discussões contemporâneas sobre desigualdade política consiste em debates filosóficos sobre a possibilidade de se atingir igualdade na governança democrática e como (Verba, 2006; Dahl, 2006; Rueschemeyer, 2004). O fato de a democracia conviver com a desigualdade política conduz à questão de se a igualdade política - na qual todos os participantes interessados têm a mesma influência nas decisões de governança - é realística; não raro conclui-se que se trata de uma fantasia e que se deve considerar aceitáveis certos limites sobre quem deve ser desigual e em que medida (Dahl, 2006; Dryzek, 1996; Meuller, 1992, p. 987-990; Verba, 2006). Como coloca Verba 
(2006, p. 505), democracias são avaliadas pelo grau de liberdades que conferem a todos os cidadãos. A hipótese subjacente é que a desigualdade política é uma dimensão lamentável e possivelmente inevitável da democracia.

Desigualdade política é também uma dimensão da estratificação social. A estratificação é uma estrutura social, definida como um padrão duradouro de comportamento que estabelece limites para os modos de pensar e agir e na qual diferenças significativas são institucionalizadas e têm longa duração. A noção de que o poder político estratifica as sociedades tem uma longa e ininterrupta história. Weber (1946) sugeriu uma dimensão exclusivamente política da estratificação, com o conceito de organização política chamado "partido"; ele afirmava que o partido é distinto de ordens de classe e de status e tem impacto direto nas possibilidades de vida. Foi Sorokin (1957) quem cunhou o termo estratificação política. Sorokin (1957) acreditava que, juntamente com as ordens econômica e ocupacional, a estratificação política impacta diretamente a mobilidade social e cultural. Apropriando-se de Weber, Lenski (1966, p. 44) afirmou que a distribuição do poder é essencial para se compreender a desigualdade. Lenski (1966) sustenta que, em sociedades de mercado modernas, o poder político está intimamente relacionado à desigualdade de riqueza, uma ideia que prenunciava uma avalanche de análises quantitativas que exploram como os recursos econômicos influenciam o processo político. Em 2004, a Força Tarefa sobre Desigualdade e Democracia Americana da Associação Americana de Ciência Política (American Political Science Association Task Force on Inequality and American Democracy) relacionou a estratificação à democracia, ao concluir que a desigualdade na capacidade de influir sobre o governo é uma função da desigualdade econômica e social.

Há profusa evidência a sustentar a perspectiva de que as organizações de governança global se caracterizam pela desigualdade política. Kofi Annan (2002, p. 140), ex-Secretário Geral da ONU, disse que não podemos afirmar que haja perfeita igualdade entre os estados membros. A desigualdade política, segundo Annan (2002, p. 140; ênfase do original), pode variar em proporção: ele afirma 
que os pequenos e impotentes sentem-se menos desiguais na ONU do que em outras grandes organizações internacionais. Não obstante, a desigualdade política em termos de voz e reação desiguais permanece como obstáculo à legitimidade das atuais instituições de governança global (ver Bexell; Tallberg; Uhlin, 2010, p. 81).

Se, como apontam Chase-Dunn e Lerro, organizações internacionais, nações individuais e movimentos sociais foram, até o momento, relativamente ineficientes na democratização de estruturas de governança global, isso pode ser sinal de que a desigualdade política doméstica se traduz em desigualdade política em âmbito global. E neste ponto, a primeira pessoa a fazer uma pergunta aos palestrantes na mencionada sessão sobre Governança Global Democrática da ISA traz um bom argumento. Como ela coloca: se movimentos sociais e governos nacionais tendem a dar pouca ênfase à igualdade das mulheres, como seria uma estrutura de governança global democrática? A autora da pergunta insinuou que a desigualdade que afeta as mulheres na esfera nacional se reproduziria em âmbito global. Ainda que surgisse um governo global (ou seja, um estado global), o problema da reprodução da desigualdade política persistiria como barreira à efetiva democratização. Em vista das desigualdades existentes nas organizações da sociedade civil, tanto no contexto nacional como no internacional, não há qualquer indício de que um estado global seria mais democrático do que o atual sistema global.

A par da desigualdade política interna às nações e entre essas ser ainda um obstáculo ao desenvolvimento democrático de estruturas de governança global, também a resistência nacionalista reduziria as possibilidades de uma governança global democrática? Nacionalistas e internacionalistas - ou, unilateralistas e multilateralistas - lutam por supremacia sobre a política externa em seus próprios países e em organizações de governança global. Pode-se imaginar um cenário em que nacionalistas vencem batalhas políticas com maior frequência que internacionalistas, e no qual o escopo das políticas formuladas por nacionalistas impossibilita ou minimiza as ações pela internacionalização. Em um mundo em que uns poucos países têm muito e a maioria deles tem pouco, a resistência nacionalista pode 
também enfraquecer o desenvolvimento democrático dessas estruturas cortando fundos de suas organizações e negligenciando as necessidades dos mais desfavorecidos. Nas palavras de Kofi Annan (2002, p. 140), Viveríamos em um mundo melhor e mais justo - de fato, um mundo mais democrático - se, em todos esses lugares, se desse um peso maior às opiniões e interesses dos pobres.

\section{Conclusão}

Este artigo pretende dar continuidade ao diálogo entre sociólogos e outros cientistas sociais sobre as expectativas em relação a uma governança global democrática. Dada a dimensão global dos problemas do mundo, várias formas de governança global já estão operando. Em vista da tendência de reprodução da desigualdade política em todos os níveis de governança, e dada a surpreendente capacidade de persistir dos nacionalistas, ambos os fatores - desigualdade política e resistência nacionalista - reduzem as possibilidades de emergência, num futuro próximo, de uma governança global democrática. E se o Conselho Intergaláctico estiver assistindo, só podemos esperar que a humanidade consiga vencer os prognósticos.

\section{Referências}

ANNAN, Kofi. Democracy as an International Issue. Global Governance, v. 8, p. 135-142, 2002.

APSA Task Force on Inequality and American Democracy. 2004. American Democracy in an Age of Rising Inequality. Disponível em: <www.apsanet.org/imgtest/taskforcereport.pdf>. Acesso em: 4 jul. 2007.

BEXELL, Magdalena; TALLBERG, Jonas; UHLIN, Anders. Democracy in Global Governance: The Promises and Pitfalls of Transnational Actors. Global Governance, v. 16, p. 81-101, 2010.

BURAWOY, Michael. (Ed.) Facing an Unequal World: Challenges for a Global Sociology. Introduction, Latin America and Africa, Volume 1. Taiwan: Instituto de Sociologia, Academia Sinica, 2010. 
CHASE-DUNN, Christopher. Social Evolution and the Future of World Society. Journal of World-Systems Research, v. 11, n. 2, p. 171-192, 2005. Disponível em: <http://jwsr.ucr.edu/archive/vol11/number2/pdf/jwsr-v11n2-chasedunn. pdf $>$. Acesso em: 14 jul. 2012.

CORTES, Soraya Vargas; DUBROW, Joshua Kjerulf.. Introdução da editora convidada: Political Inequality in Latin America. International Journal of Sociology, $v$. 41, n. 2, p. 3-9, 2011.

DAHL, Robert. On Political Equality. New Haven, CT: Yale University Press, 2006.

DRYZEK, John. Political Inclusion and the Dynamics of Democratization. American Political Science Review, v. 90, n. 3, p. 475-487, 1996.

EVANS, Peter. Counter hegemonic Globalization: Transnational Social Movements in the Contemporary Global Political Economy. In: JANOSKI, Thomas; ALFORD, Robert; HICKS, Alexander; SCHWARTZ, Mildred. (Eds.) The Handbook of Political Sociology Cambridge: Cambridge University Press, 2005. p. 655-670.

EVANS, Peter. Is an Alternative Globalization Possible? Politics \& Society, v. 36, n. 2, p. 271-305, 2008.

HOWARD, Lisa Morje. Sources of Change in United States - United Nations Relations. Global Governance, v. 16, p. 485-503, 2010.

KEOHANE, Robert O. Global Governance and Democratic Accountability. United Nations Public Administration Network (UNPAN) 2002. Disponível em: <http:// unpan1.un.org/intradoc/groups/public/documents/apcity/unpan034133.pdf>. Acesso em: 07 jul. 2012.

KRAHMANN, Elke. National, Regional and Global Governance: One Phenomenon or Many? Global Governance, v. 9, p. 323-346, 2003.

LEE, Yuan-Tseh. Challenges Facing Human Society in the 21st Century. In: BURAWOY, Michael. (Ed.) Facing an Unequal World: Challenges for a Global Sociology. Taiwan: Institute of Sociology, Academia Sinica, 2010. p. 28-34. v. 1. Disponível em: <http://www.ios.sinica.edu.tw/cna/download/proceedings/02. Lee.Opening.pdf>. Acesso em: 07 jul. 2012.

LENSKI, Gerhard. Power and Privilege: A Theory of Social Stratification. Chapel Hill: University of North Carolina Press, 1966.

MARKOFF, John. Globalization and the Future of Democracy. Journal of WorldSystems Research v. 5, n. 2, 1999. Disponível em: <http://jwsr.ucr.edu/archive/ vol5/number2/v5n2_split/jwsr_v5n2_markoff.pdf>. Acesso em: 30 jul. 2012.

MEULLER, John. Democracy and Ralph's Pretty Good Grocery: Elections, Equality and Minimal Human Being. American Journal of Political Science, v. 36, n. 4, p. 983-1003, 1992. 
MODOLO, Vanina. Political Inequality of Law: A Comparative Study of Migrant Electoral Rights in Mercosur Countries. International Journal of Sociology, v. 41, n. 2, p. 94-104, 2011.

RUESCHEMEYER, Dietrich. Addressing Inequality. Journal of Democracy, v. 15, n. 4, p. 76-90, Oct. 2004.

SOROKIN, Pitirim. Social and Cultural Mobility. New York: Free Press, 1957.

VERBA, Sidney. Fairness, Equality and Democracy: Three Big Words. Social Research, v. 73, n. 2, p. 499-540, 2006.

WEBER, Max. From Max Weber: Essays in Sociology, editado por Hans Gerth e Charles Wright Mills. New York: Oxford University Press, 1946.

WEISS, Thomas; CARAYANNIS, Tatiana; JOLLY, Richard. The 'Third' United Nations. Global Governance, v. 15, p. 123-142, 2009. 